\title{
Comfort Feeding Only: A Proposal to Bring Clarity to Decision- Making Regarding Difficulty with Eating for Persons with Advanced Dementia
}

\author{
Eric J. Palecek, MSIV*, Joan M. Teno, MD, MS ${ }^{\dagger}$, David J. Casarett, MD, MA ${ }^{\ddagger}$, Laura C. \\ Hanson, MD, MPH§, Ramona L. Rhodes, MD, MPH\|, and Susan L. Mitchell, MD, MPH\# \\ "Warren Alpert Medical School, Brown University, Providence, Rhode Island ${ }^{\dagger}$ Center for \\ Gerontology and Health Care Research, Brown University, Providence, Rhode Island \#Division of \\ Geriatrics, University of Pennsylvania, Philadelphia, Pennsylvania §Division of Geriatric Medicine, \\ University of North Carolina, Chapel Hill, North Carolina "Geriatrics Section, Division of General \\ Internal Medicine, University of Texas Southwestern Medical Center, Dallas, Texas \#Hebrew \\ Senior Life Institute for Aging Research, Boston, Massachusetts.
}

\begin{abstract}
Feeding and eating difficulties leading to weight loss are common in the advanced stages of dementia. When such problems arise, family members are often faced with making a decision regarding the placement of a percutaneous endoscopic gastrostomy tube. The existing evidence based on observational studies suggests that feeding tubes do not improve survival or reduce the risk of aspiration, yet the use of feeding tubes is prevalent in patients with dementia, and the majority of nursing home residents do not have orders documenting their wishes about the use of artificial hydration and nutrition. One reason is that orders to forgo artificial hydration and nutrition get wrongly interpreted as "do not feed," resulting in a reluctance of families to agree to them. Furthermore, nursing homes fear regulatory scrutiny of weight loss and wrongly believe that the use of feeding tubes signifies that everything possible is being done. These challenges might be overcome with the creation of clear language that stresses the patient's goals of care. A new order, "comfort feeding only," that states what steps are to be taken to ensure the patient's comfort through an individualized feeding care plan, is proposed. Comfort feeding only through careful hand feeding, if possible, offers a clear goal-oriented alternative to tube feeding and eliminates the apparent care-no care dichotomy imposed by current orders to forgo artificial hydration and nutrition.
\end{abstract}

\section{Keywords}

dementia; dysphagia; nursing home; tube feeding

\footnotetext{
Journal compilation @ 2010, The American Geriatrics Society

Address correspondence to Joan M. Teno, MD, MS, Professor of Community Health and Medicine, Center for Gerontology and Health Care Research, 121 South Main Street, Providence, RI 02912. Joan_teno@ brown.edu.

Author Contributions: All of the listed authors contributed to the preparation of the manuscript and the development of our proposed order, comfort feeding only.

Conflict of Interest: The editor in chief has reviewed the conflict of interest checklist provided by the authors and has determined that the authors have no financial or any other kind of personal conflicts with this paper.
} 
Mrs. $\mathrm{P}$ is a 92-year-old nursing home resident with advanced dementia who is nonverbal and bed-bound and cannot sit without assistance (Functional Assessment Staging of Alzheimer's Disease Stage 7D). She presents with increasing difficulty with eating. She pockets food and occasionally chokes on her food. A speech therapist has assessed her, and appropriate modification of food texture has been ordered, yet she continues to have difficulty with eating and is losing weight.

Dementia is one of the leading causes of death in the United States, accounting for more than 71,000 deaths per year.1 Unlike the dying trajectory in more-acute illnesses, persons with dementia are severely functionally and cognitively impaired for a prolonged period before death, with many developing difficulty swallowing, leading to poor oral intake, malnutrition, weight loss, and recurrent episodes of aspiration pneumonia.2,3 Reduced oral intake is expected in advanced dementia not only due to eating problems, but also as a result of the physiological consequences of the disease. One theory suggests that, because of a lower basal metabolic rate and inactivity, patients with advanced dementia have lower caloric needs. ${ }^{4}$ Additionally, as with other terminal conditions, it is expected that patients will eat less as part of the natural progression toward the end of life. Nonetheless, when eating difficulties and weight loss occur, healthcare providers and families often feel compelled to make the decision to continue hand feeding or place a percutaneous endoscopic gastrostomy (PEG) feeding tube.

The use of PEG feeding tubes to provide nutrition in patients with advanced cognitive impairment remains debatable. Despite a lack of demonstrated efficacy, approximately onethird of nursing home residents with advanced cognitive impairment have feeding tubes. ${ }^{5} \mathrm{~A}$ recent Cochrane systematic review, along with several older reviews, concluded that the use of feeding tubes, when compared with attempts at hand feeding, does not prolong survival for patients with advanced dementia, ${ }^{6-9}$ although the observational design of most studies and the lack of a randomized control trial limit these data. ${ }^{9}$ Two recent studies comparing patients with dementia with those with other diagnoses demonstrated that dementia is not, in itself, a risk factor for decreased survival after insertion of a PEG tube. ${ }^{10,11}$ In addition, one of the studies found 3-year survival to be as high as $24 \%$ for patients with dementia after PEG tube placement, although dementia stage was not specified. ${ }^{11}$ Another study showed similar survival after PEG tube placement in patients with and without dementia, although median survival was just 53 days in the dementia group. ${ }^{10}$ These recent studies suggest that further research may be warranted before the conclusion is reached that PEG tubes are never life sustaining in patients with advanced dementia.

Given the substantial cognitive and physical impairment of patients with dementia, survival may not be the only relevant outcome to consider in PEG feeding tube placement. Other perceived benefits of tube feeding include preventing weight loss and malnutrition, healing pressure ulcers, and reducing the incidence of aspiration pneumonia. Thus far, research has not demonstrated that feeding tubes benefit patients with advanced dementia in these ways. ${ }^{6-8}$ For families, preventing the patient from suffering from hunger or thirst by tube feeding may be a perceived benefit, although data from patients with other terminal diseases who can communicate such perceptions suggest that these patients do not suffer from hunger or thirst and that, when present, such symptoms can be alleviated with minimal oral intake. ${ }^{12}$ The risks and burdens of feeding tubes are significant. PEG tubes are associated with numerous adverse effects that have yet to be fully quantified; the existing literature suggests a complication rate of $32 \%$ to $70 \% .6,8$ Furthermore, to keep a PEG tube in place, patients with dementia may require physical restraint or pharmacological sedation, which may diminish quality of life. Patients with a PEG tube may also be deprived of the pleasure of eating and the human interaction that hand feeding offers. 
In summary, PEG feeding tube placement has no proven benefits for patients with advanced dementia, although the data are limited. At the same time, this intervention is associated with adverse side effects that may be particularly burdensome in these frail patients who are near the end of life.

\section{CHALLENGES IN TUBE FEEDING DECISIONS}

The Supreme Court's decision in Cruzan v. Director, Missouri Department of Health supports a patient's right to forgo PEG feeding tube insertion, through a proxy decisionmaker or advance directive, ${ }^{13}$ but despite the consensus of the literature regarding the marginal benefits of feeding tubes in patients with advanced dementia $6,7,14$ and a clear legal right to forgo a feeding tube, feeding tubes are common in patients with advanced dementia in nursing homes, whereas orders to forgo artificial hydration and nutrition are not prevalent in this population. ${ }^{5,15}$ Furthermore, national studies have shown up to a 10 -fold difference in states in the prevalence of feeding tubes in patients with advanced dementia, suggesting that factors external to the patient's disease affect feeding tube decisions. ${ }^{16,17}$ In support of this notion, studies demonstrate that specific nursing home characteristics, including size, demographics, staffing, and fiscal organization, influence feeding tube prevalence in patients with advanced dementia. ${ }^{5,18}$

Why does this vulnerable patient population have such a large number of feeding tubes placed and such a low prevalence of orders to forgo tube feeding? In part, families struggle with this decision because of the widely held notion that eating is symbolic of caregiving in our society and out of concern that, without adequate intake, patients will suffer from hunger or thirst. ${ }^{19}$ Another potential barrier is the focus of orders such as "no artificial hydration and nutrition" and "do not tube feed," which are interpreted as "no care" rather then focusing on what will be done through careful hand feeding to promote comfort and respect the wishes of the patient. These orders can present an apparent care-no care dichotomy, forcing families into a challenging position.

Regulatory scrutiny of weight loss in nursing homes also affect feeding tube decisions. Tube feeding in advanced dementia may reflect the nursing homes' misplaced attempt to respond to this regulation. In this setting, having a feeding tube in place is wrongly perceived as a defense against possible accusations of neglect and serves as an indicator that everything possible is being done to maintain nutritional intake. ${ }^{20}$

\section{REFRAMING THE DISCUSSION}

These factors that play into feeding tube decisions have contributed to the wide gap between the evidence for and the use of feeding tubes in patients with dementia. These barriers may be overcome with the creation of new language that, in addition to specifying the act of hand feeding as a viable alternative therapy, also focuses on the goals of care.

A new order, "comfort feeding only" (CFO), with the goal of providing new language to reframe discussions of managing eating problems in patients with dementia is proposed. Comfort, in CFO, has a twofold meaning. First, comfort refers to the stopping point in feeding, emphasizing that the patient will be fed so long as it is not distressing. Second, comfort refers to the goals of the feedings. The feedings are comfort oriented in that they are the least-invasive and potentially most-satisfying way of attempting to maintain nutrition through careful hand feeding. As designed, CFO provides an individualized care plan stating what nursing home staff will do to ensure the comfort of the patient during hand feeding, if possible. This order differs from other written medical orders such as do not resuscitate (DNR), do not intubate (DNI), and do not tube feed in that the focus is on what is done for the patient to promote comfort, rather than simply forgoing an action such as resuscitation, 
intubation, or tube feeding. CFO provides for continued attempts to hand feed the patient as long as it is not causing distress. In the situation in which the patient is unable to eat without significant distress, the care plan for CFO calls for a form of continued interaction with the resident, which could include assiduous mouth care, speaking to the resident, and therapeutic touch. Using the case presented above, the use of CFO in the nursing home setting is discussed.

\section{MANAGING THE CARE OF MRS. P}

The case of Mrs. P, a patient in the advanced stages of dementia with eating problems who is losing weight, is typical for patients suffering from dementia. ${ }^{3,21}$ In what follows, the decision-making and care for Mrs. P are described.

Upon recognition of her eating difficulty, a physician completes a medical evaluation of Mrs. $\mathrm{P}$ in consultation with a registered nurse, dietitian, speech pathologist, and dentist, if indicated. Evaluation includes a careful history, obtained from staff and family if necessary; physical examination; swallowing observation; and medication review. Medical evaluation excludes etiologies other than dementia ${ }^{22}$ and focuses on therapeutic interventions that may alleviate Mrs. P's swallowing difficulties. Specific interventions include altering the texture, cohesiveness, viscosity, temperature, and density of Mrs. P's food; ${ }^{23}$ changing her posture while eating, ${ }^{24,25}$ environmental modifications, ${ }^{24-26}$ denture adjustment or addressing other dental concerns; and medication adjustment.

Some patients respond to these interventions with improved oral intake and weight stabilization. Regardless of whether the patient responds favorably, ongoing education and counseling with the family is essential. The physician should speak to the family about the inevitable course of end-stage dementia to facilitate discussion of advance care planning. 27,28 As part of the advance care planning discussion, healthcare providers educate the proxy about the burdens and benefits of feeding tubes, ascertain whether the nursing home resident has preferences for the use of artificial hydration and nutrition, make recommendations, and arrive at a care plan.

In the case of Mrs. P, interventions fail to improve her oral intake. Therefore, it is time to review her previously stated wishes regarding tube feeding, if any, and to discuss the benefits and burdens of tube feeding with the appropriate surrogate decision-maker. In current practice, after this discussion, surrogate decision-makers are often provided with the option to use or refuse artificial nutrition or hydration. This presents a problematic and misleading dichotomy between "feed" or "don't feed." It is easy to see how a surrogate may agree with the physician that tube feedings do not sound consistent with the resident's wishes, but faced with a "care" or "no care" decision, he or she is unable to choose the "no care" option. As illustrated by the example discussion below, CFO functions to clarify the second option so that patients and proxies can decide between feeding through artificial nutrition or hydration and oral feeding to provide nutrition with a focus on minimizing patient distress.

$\mathrm{CFO}$ is envisioned as functioning foremost as a care order, detailing the care received during oral feedings and documenting the decision not to use a feeding tube, although in also emphasizing the broader comfort-oriented goals of feeding than with artificial nutrition or hydration, CFO allows for greater patient or surrogate empowerment in advance care planning. An example of the advance care planning discussion regarding CFO with Mr. P, Mrs. P's husband, follows. Ideally, this discussion should take place in the context of a previously established physician-surrogate relationship, in which the patient's condition and prognosis have been addressed before discussion of CFO occurs. 
Physician Mr. P, I know this might be difficult for you, but I'm sure you've noticed that your wife has been having increasing difficulties eating, and I feel it's important that we discuss what we might expect for her over the next several months. Over the past weeks, the nursing staff has noted she has been choking on the food despite modifications of the textures. This is causing her distress.

Mr. P Yeah, I noticed she's been having a harder time when I've tried to feed her as well. Do you think she'll get better?

Physician As we've discussed, dementia is a progressive illness that results in death. This means that we do not expect her condition to improve, and her condition will inevitably worsen over time.

Mr. P How much time do we have left?

Physician Well it's difficult to say exactly. I can't tell you when she will pass away, but it is something you should prepare for. Her bout with aspiration pneumonia last month and her recent difficulty swallowing, unfortunately, are not good signs. Over the next few months, we can expect that her eating difficulties will persist and may progress to the point that she is unable to safely swallow food or fluids.

Mr. P So, we'll have to put her on a feeding tube?

Physician That is an option. However, the best available evidence we have suggests that for patients such as your wife, a feeding tube would not prolong her life, reduce her chances of getting pneumonia again, or even prevent her from being malnourished. Feeding tubes also have potential adverse effects. The tube may cause her agitation, requiring us to restrain her, and malfunction of the feeding tube could require her to be transported to the emergency room. She might also experience nausea, vomiting, or reflux, and it is possible that a serious infection or severe diarrhea may require her to be hospitalized.

Mr. P That doesn't sound like the way she would want to live, but what else can we do?

Physician Another option is to focus on keeping your wife comfortable through feeding her by hand instead of through a tube. We call this order Comfort Feeding Only. The goal of this order is to focus on your wife's comfort and provide feeding to her as long as she is not showing signs of distress such as choking or coughing. If oral feeding is causing her distress, the person feeding her will stop the feeding. Over time her ability to eat orally will likely decline further. This is the natural progression as someone approaches the end of life. However, it is important for you to understand that this order of Comfort Feeding Only places a premium on her comfort during meals but is unlikely to keep her from losing weight.

Mr. P It sounds like that might be best, all considering. If it was me, I would just want to be comfortable.

Physician What do you think your wife would decide for herself if she could?

Mr. P She always told me not to let her linger or suffer when her time came, to just let her go.

Physician I understand. Based on what you told me, I recommend that she be made Comfort Feeding Only.

Mr. P Yeah, it's what she would have wanted. 
Given the advance care planning discussion with Mr. P, CFO care would be initiated in the case of Mrs. P. According to an individualized care plan, she should be fed regularly, with cessation of oral feeding when she begins to show signs of distress (e.g., choking, coughing). Her individualized care plan should document unique signs of distress, which behaviors indicate it is safe to feed, what types of foods are preferable, effective feeding techniques, and at what times of day feeding is preferable. When Mrs. P no longer tolerates oral feedings, the nursing home staff provides an alternative means of positive human interaction, in lieu of feeding, for the remainder of the meal period. Interaction may involve speaking to her and therapeutic touch, which carry a range of benefits in dementia patients. ${ }^{29}, 30$

\section{BEYOND MRS. P: CFO IN THE NURSING HOME}

Clarifying what treatment the patient receives by focusing on comfort also functions to provide nursing home staff with standards of care that are currently lacking. At present, a decision to focus on comfort and not to pursue artificial nutrition or hydration leaves Mrs. P in an unclear treatment position. Further delivery of hand feeding may not necessarily occur as a comfort-oriented approach but may consist of overly aggressive attempts at hand feeding because of institutional variation and fear of regulatory sanctions. A CFO order eliminates this ambiguity by instituting an individualized care plan linked to specific patient behaviors that directs the cessation of oral feeding at the point of patient distress. It also underscores that reduced oral intake is expected in the advanced stage of dementia and is part of the natural dying process.

The language change to CFO targets not just surrogate decision-makers, but also nursing homes and surveyors. The designation of a patient's feeding preference as CFO intrinsically communicates that the resident's goals are consistent with an approach to feeding that focuses on the patient's comfort, allowing them to eat if they are not experiencing distress. As such, the CFO order dictates that the patient is being hand fed with the goal of maximizing comfort, not maximizing oral intake. Therefore, surveyors should recognize that weight loss or malnutrition that results, although not ideal, is wholly consistent with the patient's preferences. The end goal, then, is that nursing homes may feel more comfortable not putting in a feeding tube because surveyors can more easily view hand feeding as a legitimate expression of patient values.

\section{CONCLUSION}

Patients suffering from advanced dementia with swallowing difficulties frequently do not receive the care that is consistent with their desires or best interest. This CFO proposal offers new language that highlights the goals of careful hand feeding and aims to draw the focus back to the patient by providing for an individualized care plan that prioritizes the patient's comfort. Furthermore, by detailing the specifics of the care received for patients with advanced dementia and eating problems, CFO avoids the misleading dichotomy of care versus no care. Ultimately, $\mathrm{CFO}$ provides an important language change that serves multiple purposes, including ensuring continued attempts at careful hand feeding as long as the patient is not in distress; reframing feeding tube discussions with families; and documenting to nursing homes and surveyors that the comfort of the patient during feeding is of primary importance, even in the setting of weight loss.

\section{Acknowledgments}

The authors thank Cindy Williams for her help in preparation of this manuscript. The authors would also like to thank two anonymous reviewers for their constructive comments, which considerably strengthened the manuscript. 
Sponsor's Role: None.

\section{REFERENCES}

1. Kung HC, Hoyert DL, Xu J, et al. Deaths: Final data for 2005. Natl Vital Stat Rep 2008;56:1-120. [PubMed: 18512336]

2. Sachs GA, Shega JW, Cox-Hayley D. Barriers to excellent end-of-life care for patients with dementia. J Gen Intern Med 2004;19:1057-1063. [PubMed: 15482560]

3. Kalia M. Dysphagia and aspiration pneumonia in patients with Alzheimer's disease. Metabolism 2003;52:36-38. [PubMed: 14577062]

4. Hoffer LJ. Tube feeding in advanced dementia: The metabolic perspective. BMJ 2006;333:12141215. [PubMed: 17158389]

5. Mitchell SL, Teno JM, Roy J, et al. Clinical and organizational factors associated with feeding tube use among nursing home residents with advanced cognitive impairment. JAMA 2003;290:73-80. [PubMed: 12837714]

6. Finucane TE, Christmas C, Travis K. Tube feeding in patients with advanced dementia: A review of the evidence. JAMA 1999;282:1365-1370. [PubMed: 10527184]

7. Dharmarajan TS, Unnikrishnan D, Pitchumoni CS. Percutaneous endoscopic gastrostomy and outcome in dementia. Am J Gastroenterol 2001;96:2556-2563. [PubMed: 11569675]

8. Gillick MR. Rethinking the role of tube feeding in patients with advanced dementia. N Engl J Med 2000;342:206-210. [PubMed: 10639550]

9. Sampson EL, Candy B, Jones L. Enteral tube feeding for older people with advanced dementia. Cochrane Database Syst Rev 2009:CD007209. [PubMed: 19370678]

10. Gaines DI, Durkalski V, Patel A, et al. Dementia and cognitive impairment are not associated with earlier mortality after percutaneous endoscopic gastrostomy. J Parenter Enteral Nutr 2009;33:6266.

11. Higaki F, Yokota O, Ohishi M. Factors predictive of survival after percutaneous endoscopic gastrostomy in the elderly: Is dementia really a risk factor? Am J Gastroenterol 2008;103:10111016. quiz. [PubMed: 18177448]

12. McCann RM, Hall WJ, Groth-Juncker A. Comfort care for terminally ill patients. The appropriate use of nutrition and hydration. JAMA 1994;272:1263-1266. [PubMed: 7523740]

13. Meisel A. A retrospective on Cruzan. Law Med Health Care 1992;20:340-353. [PubMed: 11651557]

14. Cervo FA, Bryan L, Farber S. To PEG or not to PEG: A review of evidence for placing feeding tubes in advanced dementia and the decision-making process. Geriatrics 2006;61:30-35. [PubMed: 16768542]

15. Mitchell SL, Kiely DK, Hamel MB. Dying with advanced dementia in the nursing home. Arch Intern Med 2004;164:321-326. [PubMed: 14769629]

16. Ahronheim JC, Mulvihill M, Sieger C, et al. State practice variations in the use of tube feeding for nursing home residents with severe cognitive impairment. J Am Geriatr Soc 2001;49:148-152. [PubMed: 11207868]

17. Teno JM, Mor V, DeSilva D, et al. Use of feeding tubes in nursing home residents with severe cognitive impairment. JAMA 2002;287:3211-3212. [PubMed: 12076216]

18. Mitchell SL, Kiely DK, Gillick MR. Nursing home characteristics associated with tube feeding in advanced cognitive impairment. J Am Geriatr Soc 2003;51:75-79. [PubMed: 12534849]

19. Hoefler JM. Making decisions about tube feeding for severely demented patients at the end of life: Clinical, legal, and ethical considerations. Death Stud 2000;24:233-254. [PubMed: 11010629]

20. Finucane TE, Christmas C, Leff BA. Tube feeding in dementia: How incentives undermine health care quality and patient safety. J Am Med Dir Assoc 2007;8:205-208. [PubMed: 17498602]

21. Volicer L, Seltzer B, Rheaume Y, et al. Eating difficulties in patients with probable dementia of the Alzheimer type. J Geriatr Psychiatry Neurol 1989;2:188-195. [PubMed: 2483945]

22. Cook IJ, Kahrilas PJ. AGA technical review on management of oropharyngeal dysphagia. Gastroenterology 1999;116:455-478. [PubMed: 9922328] 
23. Germain I, Dufresne T, Gray-Donald K. A novel dysphagia diet improves the nutrient intake of institutionalized elders. J Am Diet Assoc 2006;106:1614-1623. [PubMed: 17000194]

24. Dahlin C. Oral complications at the end of life. Am J Nurs 2004;104:404-407. quiz 8.

25. Kayser-Jones J, Pengilly K. Dysphagia among nursing home residents. Geriatr Nurs 1999;20:7782. quiz. [PubMed: 10382421]

26. Amella EJ. Factors influencing the proportion of food consumed by nursing home residents with dementia. J Am Geriatr Soc 1999;47:879-885. [PubMed: 10404936]

27. Ganzini L. Artificial nutrition and hydration at the end of life: Ethics and evidence. Palliat Support Care 2006;4:135-143. [PubMed: 16903584]

28. Karlawish JH, Quill T, Meier DE. A consensus-based approach to providing palliative care to patients who lack decision-making capacity. ACP-ASIM End-of-Life Care Consensus Panel. American College of Physicians-American Society of Internal Medicine. Ann Intern Med 1999;130:835-840. [PubMed: 10366374]

29. Kilstoff K, Chenoweth L. New approaches to health and well-being for dementia day-care clients, family carers and day-care staff. Int J Nurs Pract 1998;4:70-83. [PubMed: 9748936]

30. Camp CJ, Cohen-Mansfield J, Capezuti EA. Use of nonpharmacologic interventions among nursing home residents with dementia. Psychiatr Serv 2002;53:1397-1401. [PubMed: 12407266]

J Am Geriatr Soc. Author manuscript; available in PMC 2011 March 1. 